\title{
Right coronary occlusion during tricuspid band annuloplasty
}

\author{
Antonio M. Calafiore, MD, ${ }^{\mathrm{a}}$ Angela L. Iacò, MD, ${ }^{\mathrm{a}}$ Giovanni Bartoloni, MD, ${ }^{\mathrm{b}}$ and Michele Di Mauro, MD, ${ }^{\mathrm{a}}$ \\ Catania, Italy
}

Injury or occlusion of the right coronary artery (RCA) is a rare complication of tricuspid valve repair. We report a patient in whom the RCA was occluded by a suture during tricuspid band annuloplasty.

\section{CLINICAL SUMMARY}

A 38-year-old man was referred to the University of Catania for severe mitral regurgitation caused by bacterial endocarditis in a myxomatous mitral valve, with prolapse and chordal rupture of the posterior leaflet. The patient was symptomatic for effort dyspnea. A preoperative echocardiogram showed a dilated left ventricle with $62 \%$ ejection fraction. Moderate to severe tricuspid regurgitation was present, with a dilated annulus $(37 \mathrm{~mm})$ and right ventricle $(43 \mathrm{~mm})$. Coronary angiography results were normal. The surgical procedure included mitral repair (longitudinal plication of the posterior leaflet, suturing $\mathrm{P} 1-\mathrm{P} 2$ and $\mathrm{P} 2-\mathrm{P} 3$, positioning of artificial chords and mitral annuloplasty with a $50-\mathrm{mm}$ band, the SMB50, Sorin, Saluggia, Italy). Tricuspid repair was obtained with a 40-mm band (SMB40), positioned from the anteroseptal to the posteroseptal commissures. When the aorta was unclamped, severe ST elevation appeared immediately. Because air embolism in the RCA was suspected, systemic pressure was increased by means of vasopressors. The ST modifications were reduced, the pump was stopped, and the postoperative echocardiogram showed no mitral or tricuspid regurgitation and only mild hypokinesia in the inferior wall. During the sternal closure, ventricular fibrillation occurred; defibrillation was successful, but global hypokinesia was evident with severe ST elevation in the inferior leads. The patient was again cannulated, a segment of saphenous vein was harvested, and, under cardioplegic arrest, the 3 distal branches of the RCA were grafted and the proximal anastomosis was performed. ST modifications immediately disappeared, and

\footnotetext{
From the Departments of Cardiac Surgery ${ }^{\mathrm{a}}$ and Cardiac Pathology, ${ }^{\mathrm{b}}$ University of Catania, Catania, Italy.

Received for publication May 2, 2009; accepted for publication June 4, 2009; available ahead of print July 27, 2009.

Address for reprints: Antonio M. Calafiore, MD, Professor of Cardiac Surgery, University of Catania, Ferarrotto Hospital, Via Citelli, 95124, Catania, Italy

(E-mail: calafiore@unich.it).

J Thorac Cardiovasc Surg 2009;138:1443-4

$0022-5223 / \$ 36.00$

Copyright (c) 2009 by The American Association for Thoracic Surgery

doi:10.1016/j.jtcvs.2009.06.007
}

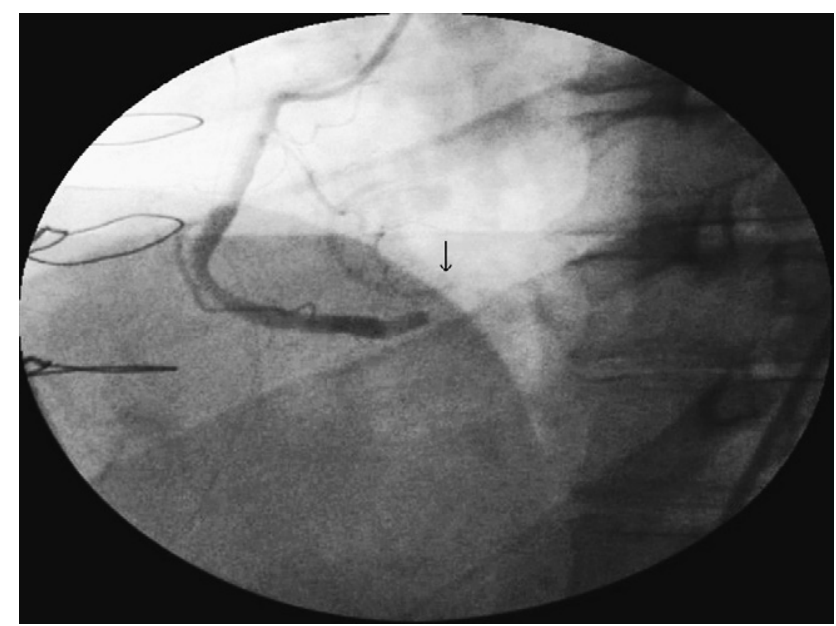

FIGURE 1. Postoperative coronarography: occlusion of the RCA at the level of the inferior end of the band, at the level of the posteroseptal commissure of the tricuspid valve (arrow).

the pump was stopped with good hemodynamics without inotropes. Peak enzymatic release was 193 creatine kinaseMB UI/L. The patient was extubated on the first postoperative day, and the postoperative course was uneventful. The echocardiogram before discharge showed no mitral or tricuspid regurgitation, ejection fraction lower than the preoperative value $(50 \%)$, and mild inferior hypokinesia. The coronarography, performed before the patient's discharge, showed complete RCA occlusion just before the posteromedial tricuspid commissure (Figure 1) and a widely patent saphenous vein graft. The level of RCA occlusion was immediately before the crux cordis.

\section{DISCUSSION}

Injuries of the RCA during tricuspid valve repair are rare; we found only 2 case reports in the literature. ${ }^{1,2}$ In the first case, acute RCA occlusion was related to ring annuloplasty; in the second case, RCA distortion occurred as a consequence of a De Vega suture annuloplasty. In all cases (where images were available), the distortion and occlusion occurred in the segment of the RCA from the acute margin to the crux, where the RCA is closer to the tricuspid annulus (Figure 2). In the present case, we reported it is clear that the occlusion point is at the level of the posteroseptal commissure, which coincides with the lower end of the band (Figure 1). It is possible that 


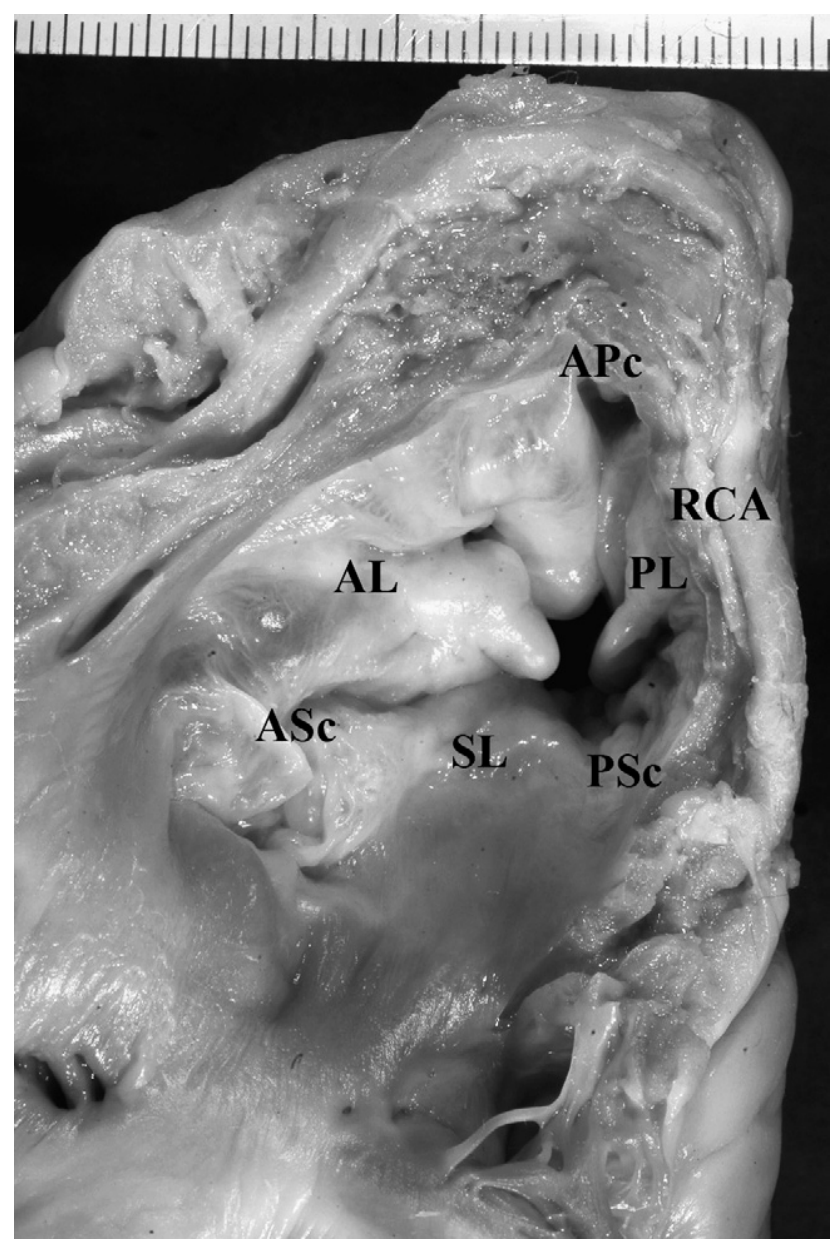

FIGURE 2. The RCA goes far from the tricuspid annulus at the level of the second half of the anterior leaflet and the first part of the posterior leaflet. In the second part of the posterior leaflet and at the level of the posteroseptal commissure, the RCA is close to the tricuspid annulus. $A L$, Anterior leaflet; $P L$, posterior leaflet; $S L$, septal leaflet; $A P c$, anteroposterior commissure; $P S c$, posteroseptal commissure; $A S c$, anteroseptal commissure. the vessel was not completely closed at the beginning, but thrombosed after protamine injection. This explains why the ST changes initially reverted and only before chest closure ventricular fibrillation and severe global hypokinesia occurred.

\section{CONCLUSIONS}

Even if uncommon, the possibility of RCA lesion during tricuspid surgery has to be taken into account, and, in case of severe arrhythmias or ST elevation, the possibility of grafting the distal RCA branches or cutting the sutures of the band to reestablish a normal blood flow has to be considered.

\section{References}

1. Rubens FD, Bedard P, Walley VM. Right coronary artery injury during tricuspid valve annuloplasty. J Cardiovasc Surg. 1990;31:533-5.

2. Symersky P, de Jong AP, Koch KT, de Beaumont EM, de Mol BAJM. Purse-string deformity of the right coronary artery: a pitfall in de Vega tricuspid annuloplasty. J Thorac Cardiovasc Surg. 2007;133:1086-7. 